\section{Experiência fora do corpo como um possível sintoma de transtorno de pânico}

\section{Out-of-body experience as a possible symptom of panic disorder}

\author{
Caro Editor, \\ Durante uma experiência fora do corpo (EFC) uma pessoa tem \\ a sensação de que o "eu" está localizado fora dos limites do corpo \\ físico e elevado de sua perspectiva visuoespacial ${ }^{1}$. Relatamos o caso \\ de uma paciente que apresentou EFC como um possível sintoma \\ associado ao transtorno de pânico (TP). \\ Uma paciente de 32 anos, casada, sexo feminino, iniciou \\ quadro de episódios súbitos, de palpitação, desconforto torácico, \\ sensação de sufocamento, parestesias, sensação de morte iminente \\ e medo de enlouquecer. Estes ocorriam espontaneamente, \\ duravam cerca de 20 a 30 minutos, e eram recorrentes. Além \\ destes sintomas, começou a experimentar episódios também \\ curtos, mas frequentes, de estar fora do seu corpo e distanciada do
}

ambiente; precisava constantemente da confirmação de familiares para ter a certeza de que não estava fora do seu corpo. Descreveu que em uma ocasião, ao andar de bicicleta, teve a sensação instantânea de estar sendo elevada no sentido vertical. Ela disse: "parecia que eu estava flutuando, conseguia ver tudo de cima e à distância”. Estas experiências eram descritas como intensas e verdadeiras, e estavam associadas à sensação de leveza, flutuação e tontura. A impressão de realidade e autoconhecimento estava preservada. Houve um agravamento dos sintomas e passou a não sair mais de casa. A paciente foi encaminhada para o nosso serviço, onde foi diagnosticado transtorno de pânico com agorafobia de acordo com os critérios do DSM-IV-TR, e iniciado tratamento com imipramina $75 \mathrm{mg} /$ dia e clorazepato dipotássico $30 \mathrm{mg} /$ dia. Após um mês de tratamento foi observada melhora significativa do quadro clínico, com desaparecimento dos ataques de pânico e dos episódios de experiências fora do corpo.

\section{Discussão}

EFCs são ilusões, definidas como sensaçōes, em que as pessoas experimentam estar fora do seu corpo físico (desincorporação), e elevado de uma perspectiva visuoespacial, podendo ou não estar associada à autoscopia, que é definida pela experiência de visualizar o próprio corpo elevado a partir desta perspectiva ${ }^{1,2}$. Ambas são classificados como fenômenos autoscópicos (FA) e podem ocorrer em diversas condições clínicas e em indivíduos normais ${ }^{1}$. Estudos 
recentes sugerem que estas resultam de um déficit transitório na integração de modalidades sensoriais (visual, tátil, proprioceptiva) e informação vestibular que contribuem para a autopercepção, ao nível da junção têmporo-parietal do córtex cerebral ${ }^{3}$.

Mohr e Blanke acreditam que pacientes com transtornos de ansiedade e despersonalização estariam mais propensos a experimentar estes fenômenos baseado nas seguintes evidências: em primeiro, estudos apontam uma associação entre despersonalização/desrealização e disfunção vestibular; em segundo, a presença de sintomas vestibulares é frequente em pacientes com transtornos de ansiedade; e, por fim, indivíduos com altos escores de despersonalização/desrealização apresentam aumento do metabolismo nos córtex temporal e têmporo-parietal, regiōes estas responsáveis pela integração do esquema corporal ${ }^{4,5}$.

Neste relato, uma possível associação entre TP e EFC é apresentada baseada nos seguintes aspectos fenomenológicos:
1) a sensação experimentada pela paciente de estar fora dos limites do seu corpo físico (desincorporação); e 2) elevada de uma perspectiva visuoespacial. Além disso, a presença de sintomas vestibulares marcantes reforça esta hipótese. Portanto, provavelmente um componente vestibular esteja envolvido nos mecanismos neurobiológicos deste subtipo específico. Embora não seja de nosso conhecimento que existam outros casos descritos na literatura, acreditamos que este sintoma seja mais frequente, porém subdiagnosticado em pacientes com TP.

Ana Claudia Rodrigues de Cerqueira, Antônio Egídio Nardi Laboratório de Respiração, Instituto de Psiquiatria, Universidade Federal do Rio de Janeiro (UFRJ), Rio de Janeiro, RJ, Brasil Instituto Nacional de Medicina Translacional (INCT-TM), Brasil

Financiamento e conflito de interesse

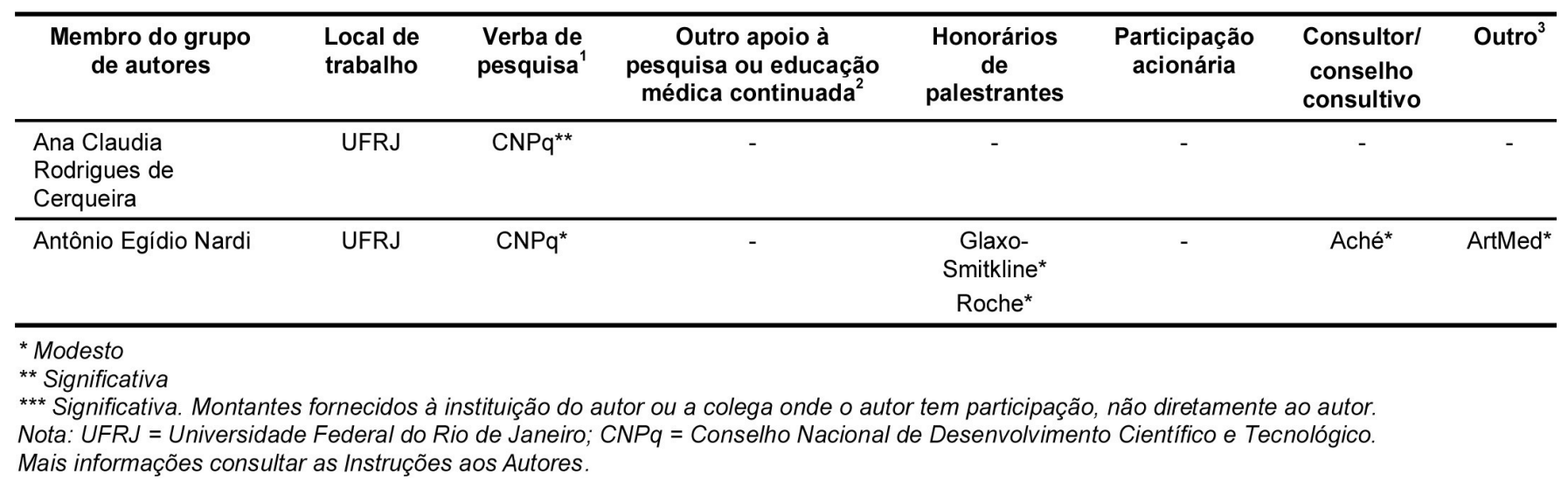

Referências

1. Blanke O, Landis T, Spinelli L, Seeck M. Out-of-body experience and autoscopy of neurological origin. Brain. 2004;127(Pt 2):243-58.

2. De Ridder D, Van Laere K, Dupont P, Menovsky T, Van de Heyning P. Visualizing out-of-body experience in the brain. NEnglJ Med. 2007;357(18):1829-33.

3. Blan ke O, Mohr C, Michel CM, Pascual-Leone A, Brugger P, Seeck M, Landis T, Thut G. Linking out-of-body experience and self processing to the temporo-parietal junction. J Neurosci. 2005; , 25(3):550-7.

4. Mohr C, Blanke O. The demystification of autoscopic phenomena: experimental propositions. Curr Psychiatry Rep. 2005;7(3):189-95.

5. Simeon D, Guralnik O, Hazlett EA, Spiegel-Cohen J, Hollander E, Buchsbaum MS. Feeling unreal: a PET study of depersonalization disorder. Am J Psychiatry. 2000;157(11):1782-8 